\title{
Anabases
}

ANABASES Traditions et réceptions de l'Antiquité

19 | 2014

Varia

\section{Karl KILINSKI, Greek myth and Western Art. The \\ Presence of the Past}

Yohann Le Tallec

\section{OpenEdition}

Journals

Édition électronique

URL : http://journals.openedition.org/anabases/4741

DOI : 10.4000/anabases.4741

ISSN : 2256-9421

Éditeur

E.R.A.S.M.E.

Édition imprimée

Date de publication : 1 avril 2014

Pagination : 351-352

ISSN : 1774-4296

Référence électronique

Yohann Le Tallec, "Karl KILINSkI, Greek myth and Western Art. The Presence of the Past », Anabases [En

ligne], 19 | 2014, mis en ligne le 01 avril 2014, consulté le 22 septembre 2020. URL : http://

journals.openedition.org/anabases/4741 ; DOI : https://doi.org/10.4000/anabases.4741

Ce document a été généré automatiquement le 22 septembre 2020.

(c) Anabases 


\title{
Karl KILINSKI, Greek myth and Western Art. The Presence of the Past
}

\author{
Yohann Le Tallec
}

\section{RÉFÉRENCE}

Karl KILINSKI, Greek myth and Western Art. The Presence of the Past, Cambridge, Cambridge

University Press, 2013, $281 \mathrm{p}$.

60 livres / ISBN 978-1-107-01332-2

1 Karl Kilinski (1946-2011) est un historien reconnu de la réception et de la réinterprétation des mythes classiques (ici recentrés autour du corpus mythologique grec) dans l'art européen et nord-américain. Il est aussi l'auteur de deux ouvrages très remarqués : Boetian Black Figure Vase Painting of the Archaic Period en 1990 suivi, en 2002, de The Flight of Icarus through Western art. Karl Kilinski prend ici acte de la remarquable plasticité des mythes grecs et de leur capacité à s'adapter à des contextes religieux et culturels très différents. L'ouvrage ne se présente pas comme une introduction à un énième opus traitant de l'histoire des arts en Occident mais plutôt comme un complément à celle-ci, la représentation des mythes grecs n'étant ici considéré ni comme un simple dispositif narratif ni comme une mise en image des sources textuelles. L'objectif de l'auteur n'est pas la recherche systématique des représentations des mythes grecs, il n'est pas non plus de repérer les différentes variations dans le temps auxquelles la réception et la réinterprétation de ces mythes donnèrent lieu. Il s'agit plutôt de cerner le type de composition et de traitement appliqués aux mythes grecs considérés comme un ensemble. Cette étude bénéficie des travaux les plus récents sur la compréhension des mythes grecs, à la fois dans leur forme et dans leur fonction. Cette étude s'inscrit d'emblée dans le prolongement de celles initiées par l'Université allemande de la fin du $\mathrm{XIX}^{\mathrm{e}}$ siècle, de Carl Robert (1850-1922) dans son ouvrage Bild und Lied paru en 1881 (les dispositifs narratifs utilisés dans la décoration des sarcophages romains y sont pour la première fois mis en relation 
avec les sources textuelles) aux travaux d'Aby Warburg (1866-1929) centrés sur le retour vers l'Antiquité perceptible dans les arts majeurs européens au XVIII ${ }^{\mathrm{e}}$ siècle. Ces deux grands précurseurs permirent de se détacher d'une analyse purement stylistique des corpus disponibles au bénéfice de travaux désormais centrés sur l'iconographie (compris comme étude méthodique des représentations plastiques d'un sujet donné dans ses relations à la fois avec ses sources littéraires et leurs significations) et sur l'iconologie entendue comme science de la représentation dans les arts des figures allégoriques, mythiques ou emblématiques, et de leurs attributs.

2 L'ouvrage s'articule ainsi autour de quatre grandes thématiques. La première interroge la nature et les origines des mythes grecs, tout particulièrement dans leurs relations avec les cycles mythologiques proche-orientaux. L'auteur s'intéresse dans un second temps aux fonctions du mythe dans l'espace grec et à son mode de transmission, notamment sous sa forme textuelle. L'auteur met ainsi en lumière le rôle opéré par les traductions latines dans l'acculturation de ces mythes à l'espace ouest-occidental et l'inflexion que celles-ci introduisirent dans la réception de ces mythes. Ces deux premiers chapitres introduisent ce qui constitue le cœur du propos de Karl Kilinski : les formes prises par les mythes grecs dans les arts plastiques en Occident et l'évolution de leur représentation jusque dans leur déclinaison cinématographique, télévisuelle ou publicitaire. La quatrième partie est une étude de cas centrée sur quelques grandes figures de la mythologie grecque: Danae, Icare, la magicienne Circé, Persée et le chasseur Actéon. Le parti-pris est ici de dégager les continuités et les ruptures dans les représentations de ces figures mythologiques. Un des intérêts majeurs de cet ouvrage est d'étendre le champ de l'étude jusqu'à la période contemporaine. Ainsi, aux côtés de représentations déjà connues et étudiées (c'est ainsi le cas du Jugement de Paris par Lucas Cranach l'Ancien ou du Diane et Actéon du Titien), Karl Kilinski s'intéresse davantage aux représentations de ces cycles mythologiques par des artistes contemporains comme Phyllis Mc Gibbon (notamment à travers une étude préparatoire à une représentation du thème de la pluie d'or sous la forme de laquelle Zeus parvint à séduire Danae), le peintre expressionniste allemand George Grosz (aquarelle de 1925 représentant Circé) ou bien encore Henri Matisse par le biais d'une illustration d'une édition de 1934 de l'Ulysse de James Joyce.

Il ressort de la lecture de cet ouvrage que la mythologie grecque a joué et exerce encore un rôle déterminant (cet aspect est précisément le plus novateur) dans la façon dont se conçoit l'art occidental. Cette étude met donc particulièrement en lumière la permanence et la récurrence de la réinterprétation de la mythologie grecque et s'attache à repérer les variations de ces représentations, à la fois dans leur champ d'application et leur herméneutique. Les exemples pris, s'ils ne visent pas à une quelconque exhaustivité, sont cependant assez nombreux pour rendre compte de la diversité des formes et des évolutions dans le mode de représentation des grandes figures de la mythologie grecque. 


\section{AUTEURS}

YOHANN LE TALLEC

ANHIMA (UMR 8820)

yletallec@netcourrier.com 